\title{
YOUTUBE VIDEO LECTURES IN UNDERGRADUATE STUDIES
}

\author{
Aleksey Baranov ${ }^{1}$, Ivan Pivovarov ${ }^{2}$
}

\begin{abstract}
The aim of this research article is to study and evaluate YouTube as an effective instrument of transmitting lecture information. The factors that motivate teachers to use YouTube in undergraduate studies are specified. Within the scopes of the research study, students were shown a YouTube video lecture before each lecture in a classroom. According to the author's idea, these YouTube video lectures contained theoretical fundamentals, which created the necessary background for lectures in the classroom, where some case studies based on theories from video lectures were discussed. During the study, students were asked about their preferences on the YouTube video lectures, factors that motivate them to watch these lectures, things they would like to improve in the video lectures, and types of video lectures they mostly like. The findings show, that an unusual background location in the video can attract the students' attention. Another conclusion that was made was that students get used to video lectures during the semester and hence by the end of the course they stop perceiving video lectures as something new. To conclude, video lectures no matter how popular they are in terms of number of views, allow teachers to use a time, which was originally planned for theory, for case studies that in many ways makes the educational process more attractive for students and practically focused.
\end{abstract}

UDC Classification Number: 378; DOI: http://dx.doi.org/10.12955/cbup.v6.1209

Keywords: YouTube, undergraduate studies, social networking website, social media, video lectures, Russia, higher education.

\section{Introduction}

More and more universities are presently seeking new methods of presenting educational content to students. According to recent studies, an increasing number of people use social media not only as an everyday tool of communication, but also in educational purposes. In these conditions, higher educational institutions try to increase the attractiveness of the educational process, with among one of the methods used being video lectures. This article depicts the implementation of YouTube video lectures in the education process in full-time study programs as well as shows an evaluation of video lectures by students.

The purpose of this article is to determine the best types of video lectures and their effectiveness as an instrument of learning. Research results can be useful for academic stuff who use video lectures or only think about using them in the future. Findings are drawn from the author, who teaches full-time courses, as well as from students participating in these courses.

\section{Literature review}

Holmes and Gardner (2006) introduce e-learning, provide an overview and discuss its applications. Friedman (2012) presents a survey paper on the use of social media in e-learning - blogs, wikis, and social networking sites. Petrovic et al. (2014) researched the educational use of Facebook and conclude that Facebook is an integral part of students' social and academic life. Nevertheless Trajkovic et al. (2012) point out that teachers who are not careful with their use of the sites might fall into inappropriate relationships with students or publicize information that must be kept private. Selwyn (2007) also researched how social networks can support the use of technology in education, however, he concluded that despite huge efforts, students and faculty make only limited use of computer technology. Eteokleouset al. (2012) examined and evaluated the role, usefulness and value of social networking, with a focus on developing Special Interest Groups within Facebook. The research of Lee and McLoughlin (2010) was focused on 3 topics: (1) the use of social network tools to build social presence, (2) how to design and create e-learning activities in distance education, and (3) the use of pedagogical strategies to support distance learners. Kent (2013) states that understanding the factors motivating students to use social media educators can develop adequate pedagogical strategies for more effective teaching and learning. The idea of Couros (2010) was to create an open, transparent and networked learning of participants based on recent trends in social media. Dalsgaard et al. (2009) discusses the potential of social networking within cooperative online education. He states that transparency is a unique feature of social networking and provides students insight into each other's actions. Daalsgard (2009) argues that the pedagogical potential of social networking is the possibility to create awareness among students. Pilli (2014) reports on the educational value of using social

\footnotetext{
${ }^{1}$ Russian Presidential Academy of National Economy and Public Administration, bav.skags@gmail.com

${ }^{2}$ Russian Presidential Academy of National Economy and Public Administration, ivan_pivovarov_@mail.ru
} 
networking sites as a Learning Management System. The first part of the paper discusses Learning Management Systems a function of learning tool, subsequently, going on to provide an in-depth discussion of the power of Social Networking System as an educational tool and concludes with a comparison of social networking websites and learning management systems. Hong (2016) continues the research on integrating social media with e-learning and concludes that creating a Facebook application that utilizes news feeds and friend listings features fully can ideally make a powerful learning platform for the user. Moreover, through the comprehensive API provided by Facebook, users "are able to harvest the learning materials and gauge the users' learning ability". Cerna and Svobodova (2017) contribute to the exploration of utilization of social media in education, elaborating three hypotheses which assume that students who can see potential for educational purposes in YouTube, Facebook and learning management system already use these applications both for study and private purposes.

\section{Methodology and Data Collection}

The research was conducted during the 2015-2016 and 2016-2017 academic years. The discipline was Organization Theory. Students who participated in the research were in their second year of study, studying a Public Administration bachelor program. Their age was between 18-19, the percentage of females varied from $62 \%$ to $71 \%$ and the number of course participants were 119 students in 2016 and 123 students in 2017.

The course contained 8 topics, each of them was supplied with a video lecture.

Video lectures were uploaded on YouTube the day before the lecture in the classroom and were accessible to everyone. In addition, the YouTube videos were also embedded in a public group on Vk.com, the most popular social media website in Russia.

The public group "Department of Management" was created by the author in January 2015, long before the current research and access to it was made open to everyone. The initial purpose of creating the group was sharing the author's educational content with students. This experience is illustrated in detail in another paper by Pivovarov (2017). After the first semester of using the VK group, students were asked to evaluate this project and one of the questions that was asked of participants was "Would you like to watch video lectures in our special interest group on VK?" As a result, $85 \%$ of participants responded that they would like to watch such videos. This was the starting point for recording YouTube video lectures.

In February 2016 and February 2017, at the very beginning of studying Organization Theory, students were invited to join the Vk.com group as well as informed that a lecture video would be coming up soon. After the first video was published the author stopped informing students about upcoming videos. Before and after each video was published the author monitored video statistics, such as number of views, likes, shares, comments as well as the time of watching.

The content of the first season of videos in 2016 was as follows: students were watching the author's talking head on a grey monophonic background mixed with infographic and schematic illustrations. The length of the videos varied from 6:50 minutes to 14:56 minutes.

In 2017, on basis of the first season's statistics, the author decided to change the format of the videos. Instead of a talking head, the author was spoke from different locations, both indoors and outdoors, while doing some activities and they were as follows: sitting in a car, doing fitness, cleaning garage, strolling down the street, walking in a park as well as running a semi-marathon. In addition, all videos were accompanied by music in the background.

Another important change was that the length of videos was significantly cut in comparison with the previous season. The length of the 2017, second season's videos varied from 1:23 minutes to 3:29 minutes.

After finishing statistics were studied, and conclusions were made.

\section{Findings}

Below you can find statistics regarding Season 1 and Season 2 of the video lectures in terms of length of video, number of likes as well as number of views.

If we try to determine a correlation between the length of Season 1 videos and number of views we hardly ever find any. As you can see in the Table 1, the most popular video is the first one despite that 
Table 1: Season 1 (average length of video - 10:31, average number of views - 95, average number of likes - 18).

\begin{tabular}{|c|c|c|c|}
\hline $\begin{array}{c}\text { Lecture } \\
\text { № }\end{array}$ & Likes & Views & $\begin{array}{c}\text { Length of } \\
\text { video }\end{array}$ \\
\hline 1 & 46 & 156 & $12: 14$ \\
\hline 2 & 30 & 98 & $14: 56$ \\
\hline 3 & 11 & 67 & $13: 58$ \\
\hline 4 & 9 & 100 & $9: 02$ \\
\hline 5 & 20 & 86 & $7: 53$ \\
\hline 6 & 9 & 110 & $12: 02$ \\
\hline 7 & 17 & 82 & $6: 50$ \\
\hline 8 & 12 & 73 & $9: 03$ \\
\hline 9 & 8 & 82 & $8: 40$ \\
\hline
\end{tabular}

Source: Authors

it is the third longest video. The fact that the first video is the most popular is quite explainable because the idea of video lectures was quite new at the time at the university in question and the students found it quite exciting. It's worth mentioning that comments appeared not only from the students to whom this video was directly addressed, but also from students who have already passed this course two years earlier. The comments to this video were as follows:

“...Incredible! Such format of studying has been desired for quite a while. Thank you very much! ..." "...The lecture is going to be interesting..."

"...Rather convenient and interesting way of presenting information. Thanks"

"...It's amazing, thank you so much, everything is perfect and what is most important clear and accessible..."

"...Thank you! Everything is quite simple and understandable..."

A second reason that can possibly explain the popularity of the first video was that students were informed about it in advance, in particular, a praepostor from each of the five study groups received a private message by a teacher. The praepostors were also informed that all students are invited to join the Department of Management group on Vk.com, where the YouTube lectures in question were embedded.

\begin{tabular}{|c|c|c|c|c|c|}
\hline & $\begin{array}{c}\text { Lecture } \\
\text { № }\end{array}$ & Likes & Views & $\begin{array}{c}\text { Length of } \\
\text { video }\end{array}$ & Background \\
\hline & 1 & 30 & 74 & $2: 44$ & no \\
\hline & 2 & 18 & 193 & $2: 11$ & Audi \\
\hline & 3 & 31 & 103 & $1: 58$ & muay-thai \\
\hline & 4 & 11 & 66 & $3: 29$ & garage \\
\hline & 5 & 15 & 111 & $2: 22$ & new house \\
\hline & 6 & 9 & 34 & $1: 23$ & no \\
\hline & 7 & 12 & 31 & $1: 25$ & no \\
\hline & 8 & 12 & 20 & $2: 24$ & no \\
\hline & 9 & 18 & 52 & $1: 36$ & marathon \\
\hline
\end{tabular}

The statistics from Season 2 shows us once again that the length of the videos and the number of views are hardly related. The more important factor of popularity, however, still not decisive was background of videos. For instance, the most popular videos of Season 2 (Lecture 2 and Lecture 3 respectively) were recorded in untypical locations: Lecture 2 (Motivation Theories) was done in a cockpit of car, specifically an expensive car of business class with a purpose to show students a particular example of material motivation, while Lecture 3 demonstrated the teacher doing muay thai training in a fitness club as the topic was about Organizational Strategies and author was going to analyse business strategy of the fitness club in question. Surprisingly, Lecture 9, containing a video of 
the author, running a semi-marathon, was not at all among the videos leading in popularity. This fact demonstrates to us that an unusual background in the video can attract the students' attention in some extent, but its role is much more limited that it was originally expected by the author.

\section{Conclusions and Discussion}

The findings of this research lead us to a few important conclusions and discussions.

Discussion 1 - is it necessary to regularly inform students about upcoming videos? The number of views and likes of Lecture 1 Season 1 ( $1^{\text {st }}$ position in both categories) shows us that informing students can be really important however, when looking at Lecture 1 Season 2 neither leads in likes, nor in the number of views. Lecture 2 and Lecture 3 (both Season 2) prove that a background in video or an unusual location can really attract the students' attention.

Discussion 2 - why Season 1 videos were more popular than Season 2 videos in terms of number of views despite the fact that Season 1 videos were longer and the background in them was not as unusual as in Season 2 videos? An assumption can be made that students who had already finished the study course in question, shared information about it and about video lectures, in particular, with their younger classmates and, as a result, the younger students were not as much surprised or interested as their senior fellows when they found out that their traditional classroom lectures will be accompanied by video ones. Another suggestion that can be made is that students during the semester got used to video lectures, and hence, by the end of the course they stop perceiving video lectures as something new. As a result, videos started losing their attractiveness to students.

Finally, the most important conclusion that can be done based on the current research is that video lectures, no matter how really popular they are in terms of views number, allow teacher to use a time, originally planned for theory, for case studies, that makes the educational process more attractive for students and practically focused. Moreover, some students confessed during private talks that video lectures are very comfortable way of getting the information in case you did not attend a lecture.

\section{References}

Allen, I. E. and Seaman, J. (2010). Class differences: Online education in the United States, 2010. Sloan Consortium. Retrieved from http://sloanconsortium.org/publications/survey/class_differences

Allen, I. E., \& Seaman, J. (2011). Going the distance: Online education in the United States. Babson Survey Research Group and Quahong Research Group, LLC

Cerna M., Svobodova L. (2017). kUtilization and expected potential of selected social applications in setting - a case study. In: Uskov V., Howlett R., Jain L. (eds.). Smart education and e-learning, Springer.

Christensen,C.M.(1997)TheInnovator'sDilemma:WhenNewTechnologiesCauseGreat

FirmstoFail,HarvardBusinessSchoolPress,Boston,MA.

Coklar, A.N. (2012) Evaluations of Students on Facebook as an Educational Environment. Turkish Online Journal of Qualitative Inquiry, April 2012, 3(2).

Couros, A. (2010) Developing Personal Learning Networks for Open and Social Learning, Emerging Technologies in Distance Education. G. Veletsiano (Ed) AU Press, Athabasca University.

Dalsgaard, P. (2009). Transparency in Cooperative Online Education, The International Review of Research in Open and Distance Learning, Vol. 10, No 3.

Eteokleous, N., Ktoridou, D., Stavrides, I., Michaelidis, M. (2012) Facebook - a social networking tool for educational purposes: developing special interest groups. In: ICICTE 2012 Proceedings

Flavin, M. (2012) Disruptive technologies in higher education. In: ALT-C 2012 Conference Proceedings.

Friedman, L.W. (2012) Using social media technologies to enhance online learning. Retrieved from http://www.thejeo.com/Archives/Volume10,Number1/Friedman.pdf

Holmes, B., Gardner,J.(2006) E-learning concepts and practice. Sage Publications.

Hong, J.L. (2016). Integrating Social Networking Sites with E-Learning. In: Tang S., Logonnathan L. (eds). Assessment for Learning Within and Beyond the Classroom. Springer, Singapore.

Kent, M. (2013) Changing the Conversation: Facebook as a Venue for Online Class Discussion in Higher Education. MERLOT Journal of Online Learning and Teaching Vol. 9, No. 4.

Lee, M.J.W., McLoughlin C. (2010) Beyond Distance and Time Constraints: Applying Social Networking Tools and Web 2.0 Approaches in Distance Education. Emerging Technologies in Distance Education. G. Veletsiano (Ed) AU Press, Athabasca University

Montoneri, B. (2015) Impact of Students' Participation to a Facebook Group on their Motivation and Scores and on Teacher's Evaluation. The IAFOR Journal of Education, Volume III - Issue I - Winter 2015. 
Petrovic, N., Jeremic V., Cirovic M., Radpjicik Z., Milenkovic N. (2014) Facebook vs Moodle: what do students really think? International Conference on Information Communication Technologies in Education.

Pilli, O. (2014). LMS Vs. SNS: Can Social Networking Sites Act as a Learning Management Systems? American International Journal of Contemporary Research, Vol. 4, No. 5, pages 90-97.

Selwyn, N. (2007). The use of computer technology in university teaching and learning: a critical perspective. Journal of Computer Assisted Learning. Volume 23, Issue 2, pages 83-94, April 2007.

Trajkovic V. (2012) Increasing Students' Motivation by Using Social Networks In And Out of the Classroom. In: ICT Innovations 2012 Web Proceedings, p. 17-24. 